\title{
Observed anomalous upwelling in the Lakshadweep Sea during the summer monsoon season of 2005
}

\author{
V. V. Gopalakrishna, ${ }^{1}$ R. R. Rao, ${ }^{2}$ K. Nisha, ${ }^{1}$ M. S. Girishkumar, ${ }^{2}$ T. Pankajakshan, ${ }^{1}$ \\ M. Ravichandran, ${ }^{3}$ Z. Johnson, ${ }^{4}$ K. Girish, ${ }^{4}$ N. Aneeshkumar, ${ }^{4}$ M. Srinath, ${ }^{5}$ S. Rajesh, ${ }^{1}$ \\ and C. K. Rajan ${ }^{4}$ \\ Received 22 March 2007; revised 27 December 2007; accepted 4 February 2008; published 2 May 2008.
}

[1] Repeat near-fortnightly expendable bathythermograph (XBT) transects made along Kochi-Kavaratti (KK) shipping lane in the Lakshadweep Sea (LS) during 2002-2006 are examined to describe the observed year-to-year variability of upwelling during summer monsoon season (SMS). Among all the years, the upwelling characterized by up-sloping of $25^{\circ} \mathrm{C}$ isotherm is relatively weaker and persisted until November during SMS of 2005 and is stronger during the SMS of 2002. As a result of prolonged upwelling, the sea surface temperature has shown cooling extending into the postmonsoon season. The estimated marine pelagic fish landings along the southwest coast of India (SWCI) have also shown increase until December. The governing mechanisms both in terms of local and remote forcings are examined to explain the observed anomalous upwelling during SMS of 2005. The equatorward alongshore wind stress (WS) along the KK XBT transect persisted in a transient manner beyond September only during SMS of 2005. The westerly wind bursts over the equator during the winter of 2004-2005 are both short-lived and relatively weaker triggering weaker upwelling Kelvin waves that propagated into LS in the following SMS of 2005. The observed distribution of negative sea surface height anomaly in the LS is relatively weaker during the SMS of 2005 and lasted longer. The correlation analysis suggests that the local alongshore WS off the SWCI and the remote forcing from the southern coast of Sri Lanka has greater influence on the observed interannual variability of upwelling in the LS when compared to the remote forcing from the equator.

Citation: Gopalakrishna, V. V., et al. (2008), Observed anomalous upwelling in the Lakshadweep Sea during the summer monsoon season of 2005, J. Geophys. Res., 113, C05001, doi:10.1029/2007JC004240.

\section{Introduction}

[2] The Lakshadweep Sea (LS) situated between the southwest coast of India and the Lakshadweep Island chain in the South Eastern Arabian Sea (SEAS) exhibits strong seasonal variability both in the hydrography and circulation under the influence of seasonally reversing monsoons [Cutler and Swallow, 1984; Johannessen et al., 1987]. The region off the southwest coast of India is one of the most biologically productive regions of the world oceans contributing to large volumes of fishery resources due to well known upwelling process during the SMS [Madhupratap et al., 1994, 1996, 2001]. Historically several studies have been reported in the literature to describe and explain the observed upwelling off the southwest coast of India [Banse,

\footnotetext{
${ }^{1}$ National Institute of Oceanography, Goa, India.

${ }^{2}$ Naval Physical and Oceanographic Laboratory, Kochi, India.

${ }^{3}$ Indian National Centre for Ocean Information Services, Hyderabad, India.

${ }^{4}$ Department of Atmospheric Sciences, Cochin University of Science and Technology, Kochi, India.

${ }^{5}$ Central Marine Fisheries Research Institute, Kochi, India.

Copyright 2008 by the American Geophysical Union. 0148-0227/08/2007JC004240
}

1958, 1968; Sharma, 1968; Shetye, 1984; McCreary and Chao, 1985; Johannessen et al., 1987; Shetye et al., 1990; Shankar et al., 2005]. All these studies based on relatively sparse and limited hydrographic data sets reported the onset of upwelling in the deeper depths as early as February/ March, that gradually reaches the near-surface layers by May and continues until September in association with southward flowing surface coastal current [Sharma, 1968; Shetye, 1984; Johannessen et al., 1987]. The alongshore wind stress and wind stress curl have been identified as the most important local forcings responsible for the occurrence of upwelling through Ekman dynamics during the SMS [Shetye et al., 1985; Shetye and Shenoi, 1988]. The upwelling first appears in the southern latitudes along the southwest coast of India and progressively advances poleward in association with the northward propagating upwelling coastal Kelvin waves during the premonsoon season resulting in maximum upwelling off Kochi [McCreary et al., 1993; Shankar and Shetye, 1997]. The multilayer numerical models driven by climatological winds that simulated the ocean circulation in the north Indian Ocean have demonstrated the importance of remote forcing from the equator through propagating Kelvin and Rossby waves [Clarke, 1983; Potemra et al., 1991; Yu et al., 1991; McCreary et al., 


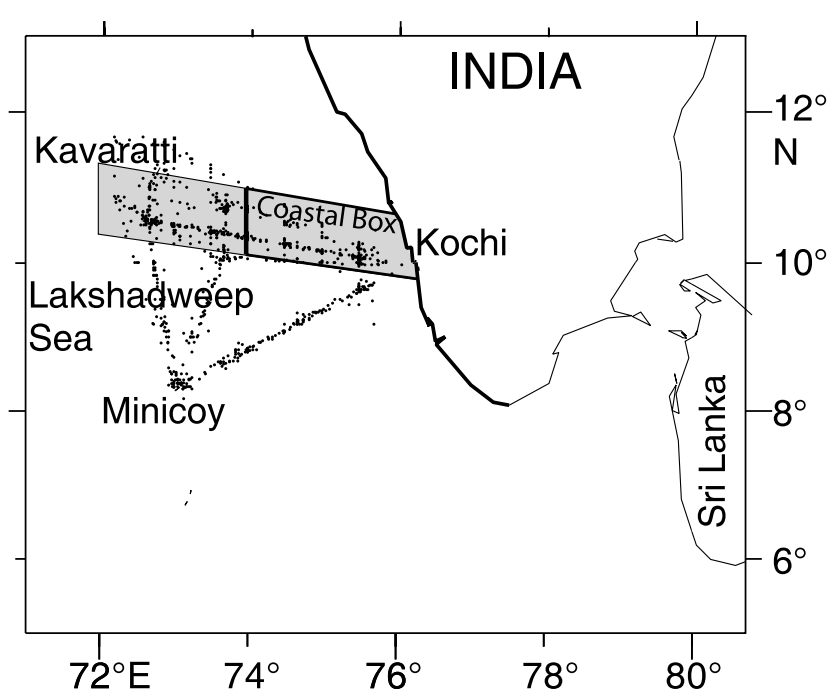

Figure 1. Black dots represent XBT stations collected in the LS during May 2002 to December 2006. Densely covered Kochi-Kavaratti XBT transect is shown by the shaded strip. A coastal box $\left(9.5^{\circ} \mathrm{N} / 76^{\circ} \mathrm{E}, 10.5^{\circ} \mathrm{N} / 76^{\circ} \mathrm{E}\right.$, $11^{\circ} \mathrm{N} / 74^{\circ} \mathrm{E}, 10^{\circ} \mathrm{N} / 74^{\circ} \mathrm{E}$ ) is chosen to examine the upwelling characteristics. Dark coastline represents the southwest coast of India chosen to relate the total pelagic fish landings with the observed upwelling.

1993, 1996; Bruce et al., 1994; Shankar and Shetye, 1997; Han and Webster, 2002]. In the present study, the systematic repeat XBT measurements made at near-fortnightly intervals along the KK XBT transect in the LS over a period of five years continuously from May 2002 to December 2006 for the first time are utilized to examine the observed yearto-year variability of the near-surface thermal structure and the associated upwelling in the LS. The anomalous upwelling noticed during the SMS of 2005 is studied in some detail utilizing the available satellite data on surface winds, sea surface height (SSH) anomaly, and sea surface temperature (SST). The paper is organized as follows. In section 2, both in situ and remotely sensed data sets utilized in this study are described. A brief description of the observed annual cycle of near-surface thermal fields and the related features are presented in section 3 . The probable governing mechanisms both in terms of local and remote forcings that drive the upwelling are addressed in section 4 . The salient results are summarized in section 5 .

\section{Data}

[3] Under a major ongoing long-term observational program in the Indian seas supported by the Ministry of Earth Sciences, Government of India, repeat near-fortnightly XBT measurements are being carried out systematically in the LS for the first time since May 2002 using passenger ships that ply regularly between Kochi and Lakshadweep Island Chain. During each XBT survey (M/s. Sippican T7 XBT probes and Mark-21 XBT data acquisition system), a minimum of 10-13 vertical temperature profiles are collected sampling the upper $760 \mathrm{~m}$ water column at $50 \mathrm{~km}$ interval (black dots in Figure 1 depict the XBT stations). The KK XBT transect (shaded strip in Figure 1) is the most densely covered transect utilized to construct snapshot vertical thermal sections in the upper $150 \mathrm{~m}$ water column to characterize the nature of the observed year-to-year variability of the upwelling. This systematically collected $\mathrm{XBT}$ data set is unique in several respects to examine the observed seasonal cycle of near-surface thermal structure and its most important embedded feature, upwelling. The depth of $20^{\circ} \mathrm{C}$ (D20) isotherm drawn form temperature climatology [Locarnini et al., 2006] is utilized to characterize the propagating Kelvin waves along the equator. The AVISO girded SSH anomaly product for the period January 2002 to December 2006 was utilized to characterize the nature of propagating upwelling Kelvin and Rossby waves. The QuikSCAT wind data (seasonal cycle removed) are utilized to characterize both the equatorial and alongshore wind stress and wind stress curl. The TMI SST data for the KK XBT transect are used to examine the observed cooling caused by the upwelling during these five years. Monthly estimates of total marine pelagic fish landings along the southwest coast of India (coastline is shown as a dark line in Figure 1) for the years 2002-2005 are examined to seek relationship between the fish landings and the upwelling characteristics.

\section{Analysis}

[4] The individual snapshot vertical thermal sections along KK XBT transect for the years 2002-2006 are shown in Figure 2. Although the XBT data are collected at nearfortnightly intervals, only one typical representative section is chosen for each month for all these years. The annual cycle is typically characterized by deep near-surface isothermal layer during winter caused by downwelling [Shenoi et al., 2005]. Thermal inversions in the nearsurface layer are also seen during November-February with some differences between years [Thadathil and Gosh, 1992; Gopalakrishna et al., 2005]. All the thermal sections show the occurrence of a warm pool [Rao and Sivakumar, 1999; Shenoi et al., 1999] during March-May during all the years with minor differences in the intensity. With the onset and progress of the summer monsoon the warm pool collapses with some differences among the years of study. A mild secondary warming is noticed again in the nearsurface layer during October-November after the withdrawal of the summer monsoon. Below the surface layer, the thermocline also shows a pronounced annual cycle. The deep thermocline seen during winter (December-February) begins to shoal from February/March reaching its shallowest depth by September due to upwelling. During the upwelling season, the near-surface isothermal layer progressively shoals with increasing magnitude toward the coast [Sharma, 1968, Shetye et al., 1990; Shankar et al., 2005; Shenoi et al., 2005]. During the SMS of 2005 (SMS of 2002), the observed upwelling is weaker (stronger) than that of observed in any other year. Further, the upwelling during the SMS of 2005 persisted until November, which is two months longer than the normal. The probable reasons for the anomalous upwelling observed during the SMS of 2005 are examined in the subsequent sections.

[5] The topography of depth of $25^{\circ} \mathrm{C}$ isotherm (D25) representing the core of the thermocline is extracted from the near-fortnightly snap shot thermal sections for all the five years. The annual cycle of D25 for a coastal box 


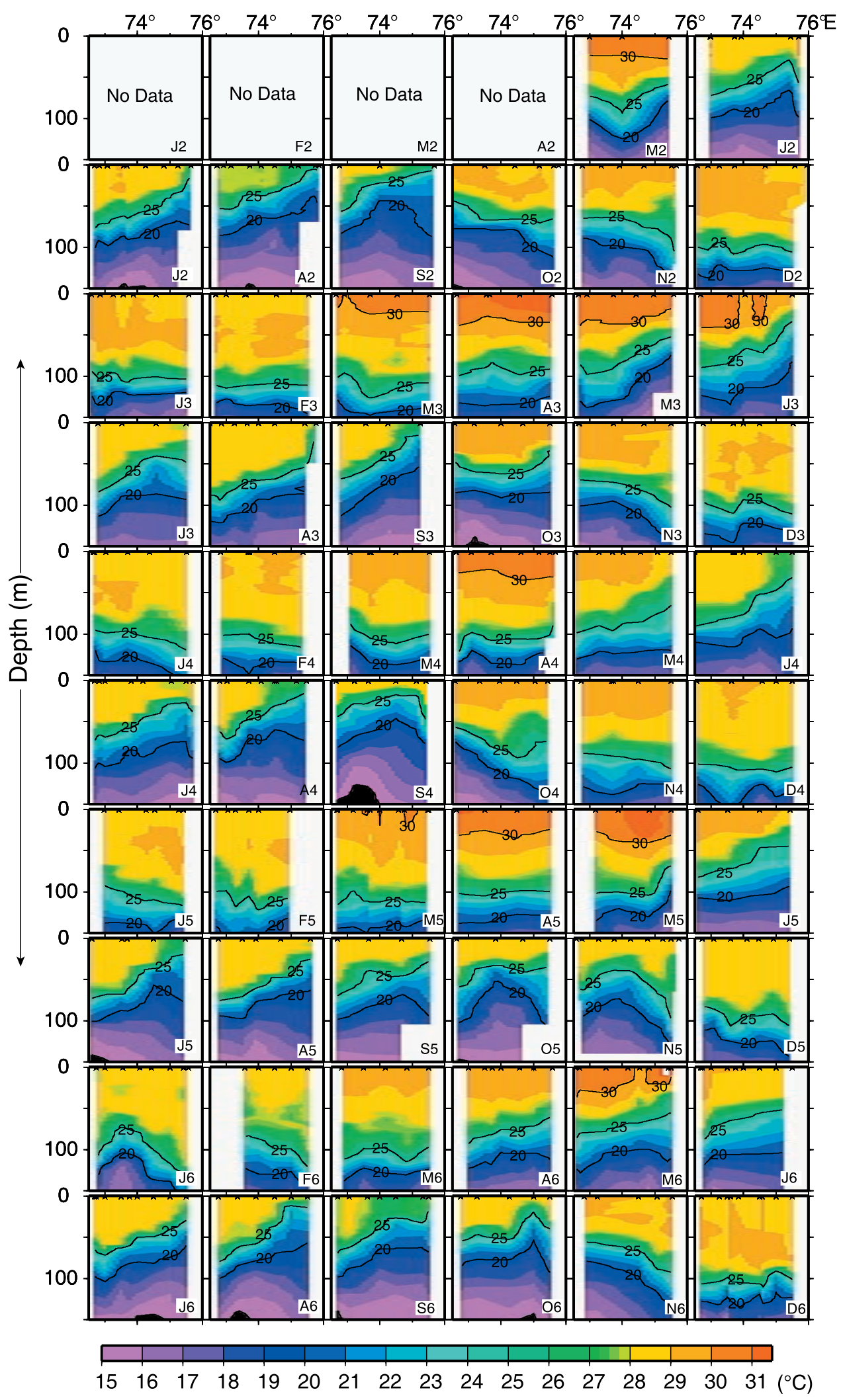

Figure 2. Annual cycle of snapshot vertical thermal sections along KK XBT transect in the upper $150 \mathrm{~m}$ during 2002-2006. J2-D2, J3-D3, J4-D4, J5-D5, and J6-D6 represents January-December individual snapshot vertical thermal sections for the years 2002, 2003, 2004, 2005, and 2006, respectively. J2 represents January 2002, F2 represents February 2002 and so on until December 2002. The same is followed for the other years. 


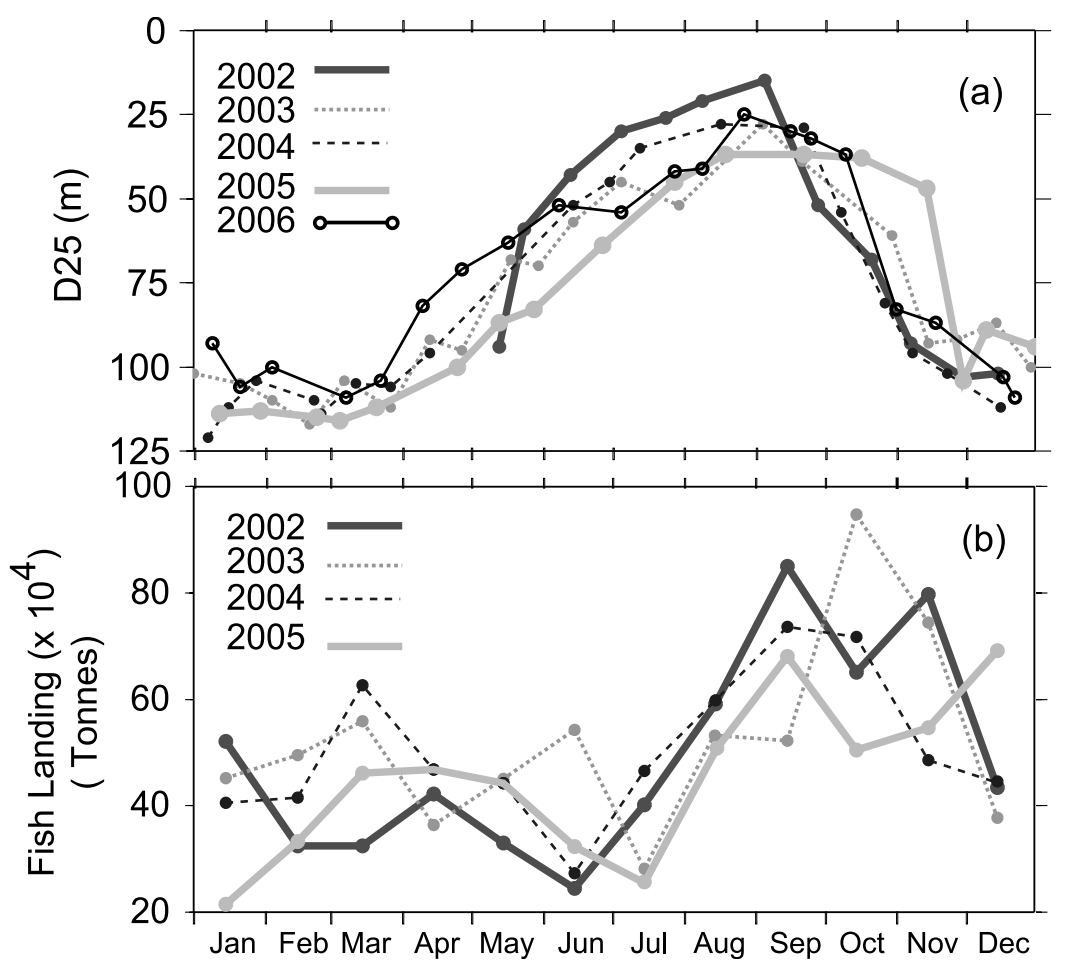

Figure 3. Annual march of (a) D25 (m) for the coastal box (shown in Figure 1) for the years 20022006 and (b) monthly total pelagic fish landings (tonnes) along the southwest coast of India (dark coastline shown in Figure 1) for the years 2002-2005.

(shown in Figure 1) is presented in Figure 3a as upwelling is more pronounced toward the coast [Shetye et al., 1990] to highlight the observed differences in upwelling among these five years. Although the uplift of D25 has started as early as February/March, the upwelling is weaker (stronger) during the SMS of 2005 (SMS of 2002) compared to all the other years (Figure 3a). During the SMS of 2002, the D25 reached the shallowest depth of about $15 \mathrm{~m}$ during August, the lowest value recorded in the entire data set. However, during the SMS of 2005, the D25 reached the shallowest depth of only $38 \mathrm{~m}$ during November, that is about two months later than the normal indicating a weaker and prolonged upwelling.

[6] As the upwelling process and the pelagic fishery production are strongly coupled [Madhupratap et al., 1994, Srinath et al., 2006] the reported pelagic fish landings along the southwest coast of India are examined for the years 2002-2005. The annual cycle of the estimated fish landings with a coefficient of variance of $5-10 \%$ (Figure $3 b$ ), clearly shows a progressive increase from June-July to SeptemberOctober in all the years with the exception of 2005 [Srinath et al., 2006]. During this year the annual total fish landings of $53 \times 10^{4}$ tons are lower than the averaged (2002-2004) landings of $61 \times 10^{4}$ tons in agreement with the observed weak upwelling during the SMS of 2005. In general, during the normal years, the fish landings begin to recede from September-October after reaching their peak intensity. However, it is only during 2005, the fish landings showed an increase until December unlike any other year in close agreement with the prolonged upwelling.

[7] The observed SSH anomaly along the KK XBT transect is examined to characterize the signature of up- welling/downwelling and of the propagating waves. The observed annual cycle of SSH anomaly along the KK XBT transect for all the five years (Figure 4) clearly shows distinct differences in the amplitude and the temporal extent of the signature caused by the westward propagating Rossby waves triggered by the northward propagating coastal Kelvin waves. During the upwelling season, the SSH anomaly is negative owing to the contribution from the steric effect and upwelling Kelvin waves. The change of sign of SSH anomaly occurs during May as seen in all the years. Interestingly, this change of sign has occurred a little later and the negative values lasted longer during 2005. In addition, the magnitudes of these negative values are also relatively weaker during the SMS of 2005 compared to any other year. This implies that the amplitude of the propagating waves and upwelling is relatively weaker during the SMS of 2005 resulting in relatively weaker uplift of D25. The SSH anomaly during the SMS of 2002 is relatively stronger suggesting stronger upwelling as seen in the XBT measurements.

[8] The sea surface cooling is usually associated with upwelling [Shetye et al., 1990]. Accordingly the annual cycle of SST along the KK XBT transect derived from TMI is examined for all the five years (Figure 5). The annual cycle of SST is typically characterized a primary (secondary) heating maxima during premonsoon (postmonsoon) season. The primary (secondary) cooling maxima occur during the summer (winter) monsoon season. However, there are distinct differences in the distribution of heating and cooling cycles among these five years. The most noteworthy feature is the very weak secondary warming during October-November 2005 unlike any other year. 

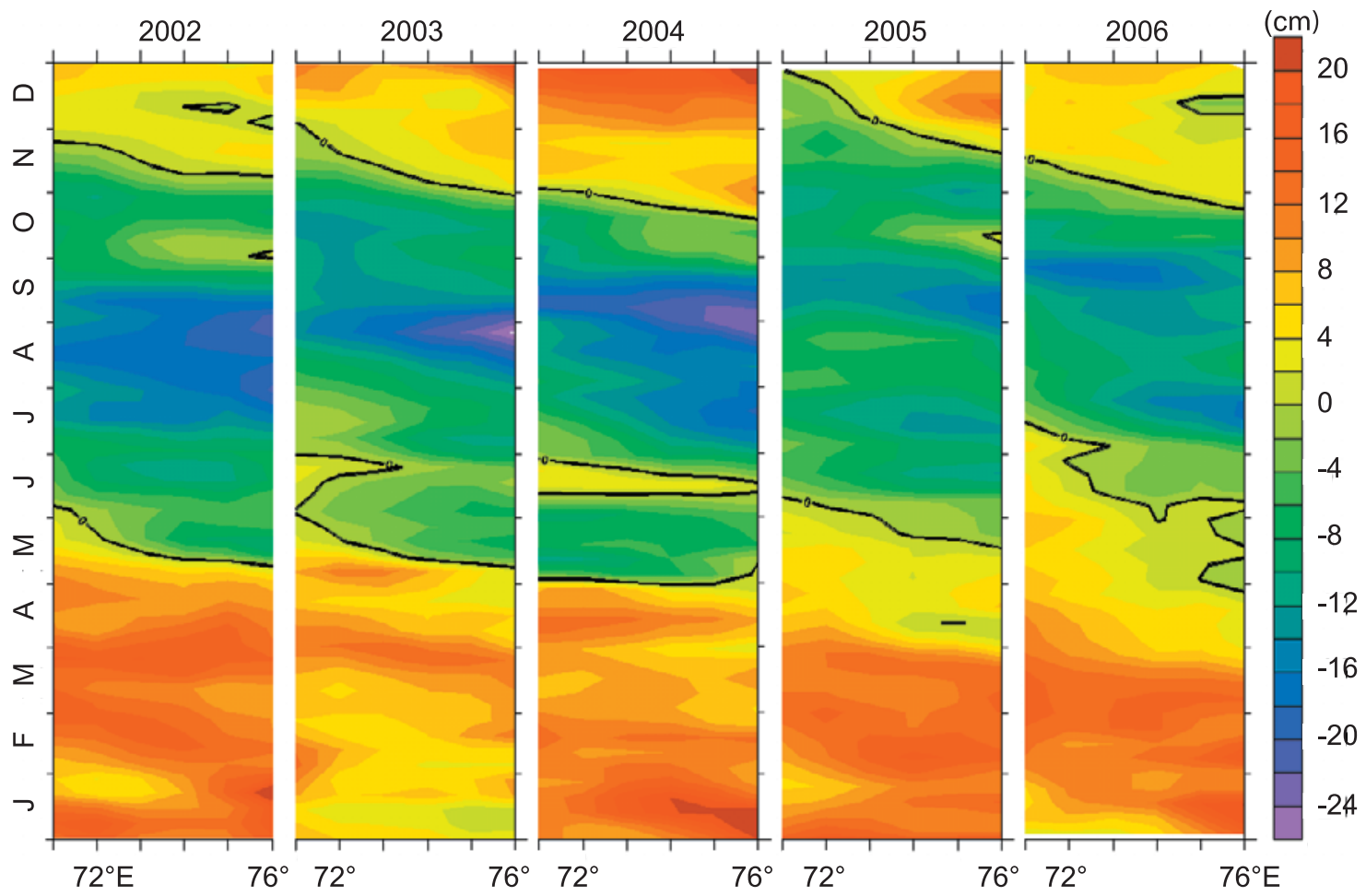

Figure 4. Evolution of SSH anomaly (centimeters) along the KK XBT transect for the years 2002-2006.

This anomalous feature is also noticed in the near-surface thermal structure along KK XBT transect during OctoberNovember 2005 (Figure 2). During 2005 the cooling episodes continued beyond the SMS and persisted until the end of the year. This is in excellent agreement with the prolonged upwelling inferred from both the vertical thermal sections and the SSH anomaly fields. Shetye et al. [1990] has reported an SST decrease of $2.5^{\circ} \mathrm{C}$ off Kochi when

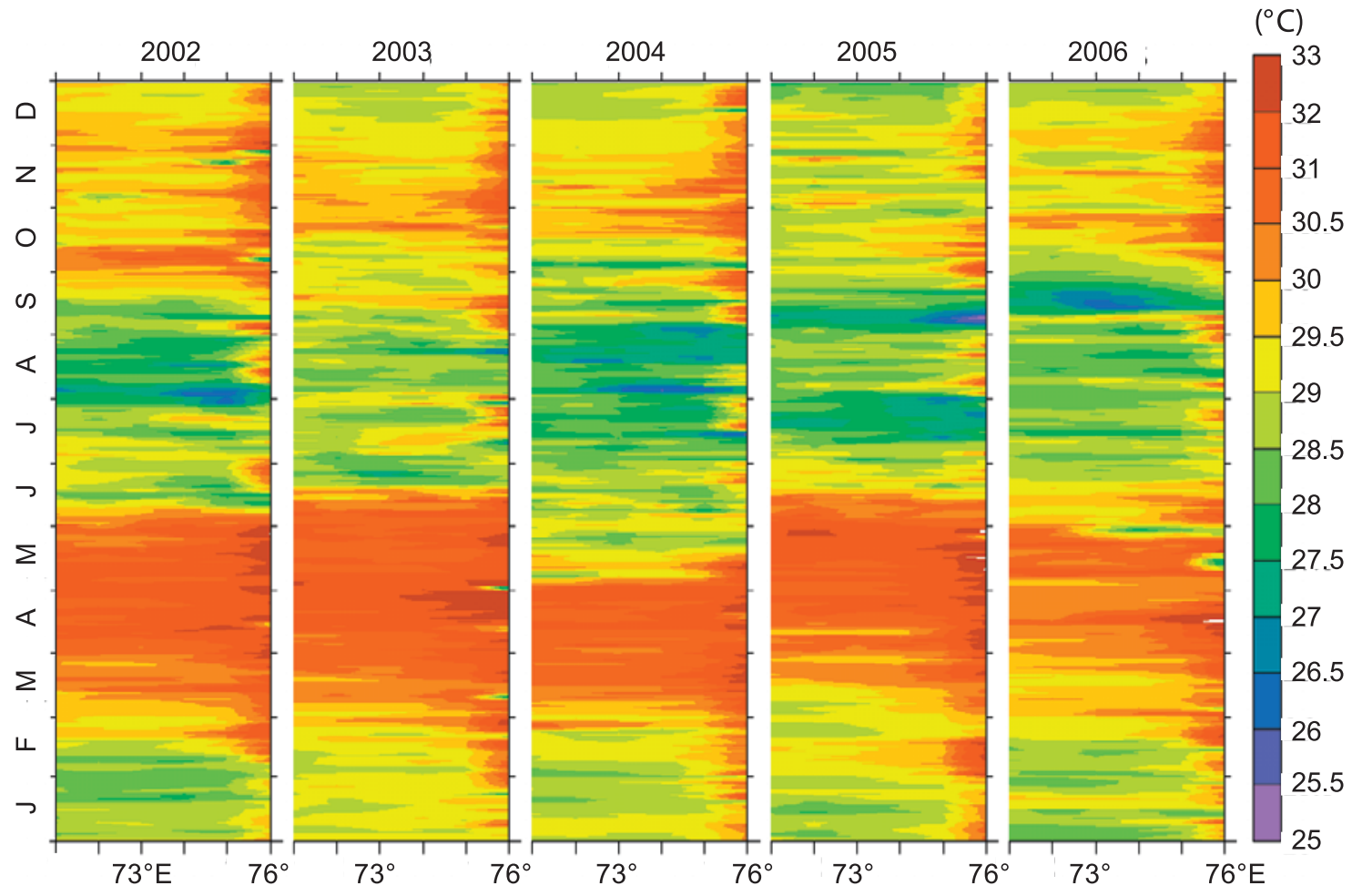

Figure 5. Evolution of TMI mean monthly SST $\left({ }^{\circ} \mathrm{C}\right)$ along the $\mathrm{KK}$ XBT transect for the years $2002-2006$. 


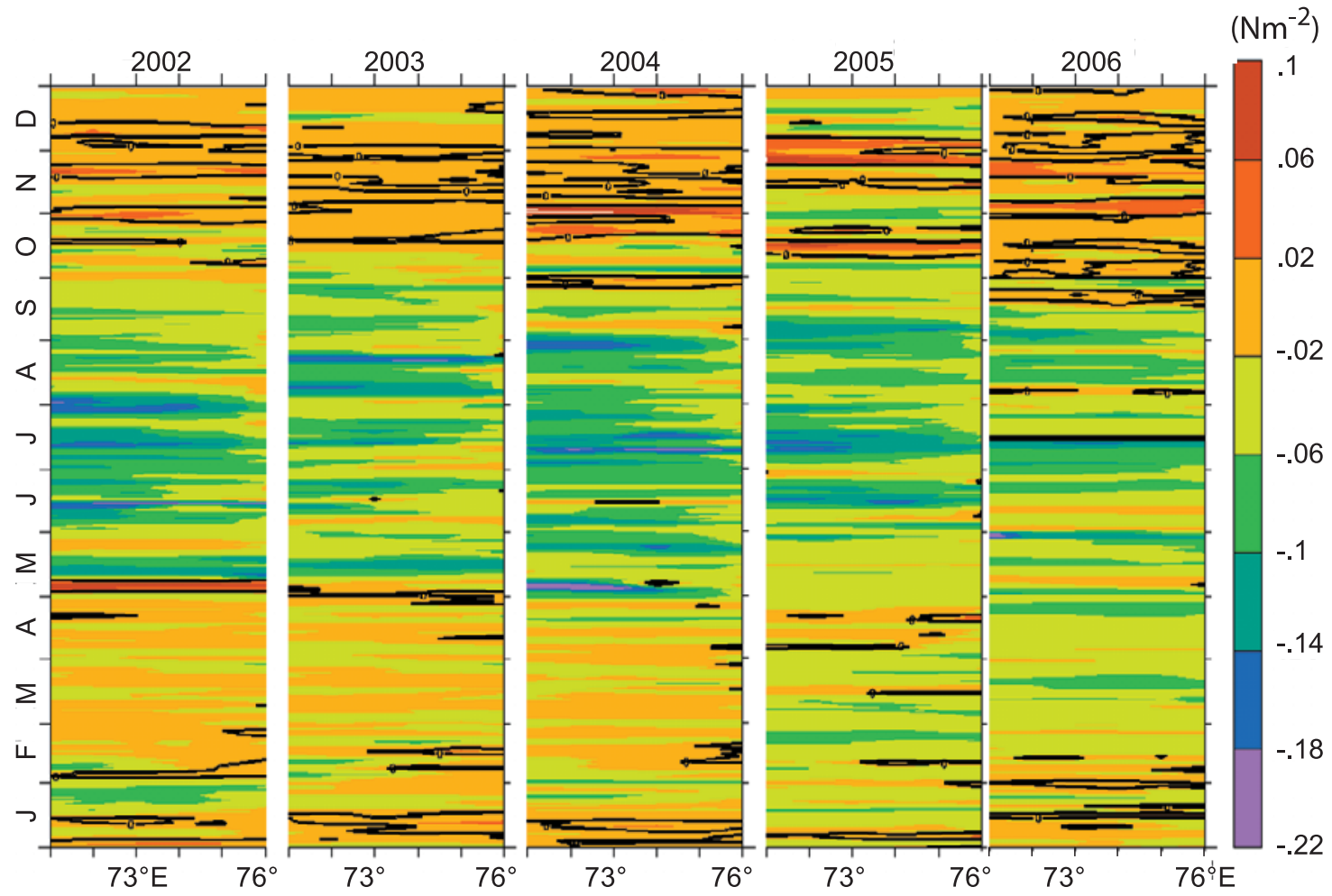

Figure 6a. Evolution of QuikSCAT along-shore wind stress $\left(\mathrm{N} \mathrm{m}^{-2}\right)$ component along the KK XBT transect for the years 2002-2006.

compared with offshore waters during SMS of 1987 due to upwelling. The XBT data showed a SST decrease of $2.9^{\circ} \mathrm{C}$ $\left(0.4^{\circ} \mathrm{C}\right)$ during the SMS of 2002 (SMS of 2005).

\section{Governing Mechanisms}

\subsection{Local Forcing}

[9] It is important to understand the possible mechanisms that produce the observed anomalous nature of upwelling during the SMS of 2005. It is well known that the local winds play an important role in driving the offshore Ekman transport and the associated divergence in the near-surface layers leading to the uplift of isotherms in the thermocline [Shetye et al., 1985]. Accordingly the annual cycle of both the observed alongshore wind stress and wind stress curl are examined for the KK XBT transect for all the five years (Figure 6a). The alongshore wind stress is equatorward during the SMS of all the years. Interestingly, unlike other years the equatorward wind stress has persisted until the end of December in a transient manner only during 2005. A comparison of Ekman pumping velocity in the coastal box during SMS of 2002 and SMS of 2005 clearly shows that the positive Ekman pumping driven by the surface wind stress curl on episodic timescales is more pronounced during the SMS of 2002 (thick line) in comparison to the SMS of 2005 (thin line) (Figure 6b). This also lends support to the inference drawn from the XBT thermal sections. Thus the present analysis has clearly revealed that the local windforcing is distinctly different during the SMS of 2002 and SMS of 2005 resulting in differences in the observed upwelling characteristics.

\subsection{Remote Forcing}

[10] The recent modeling studies have clearly shown that the winds over the equatorial Indian Ocean play an important role in modulating the circulation features of the north

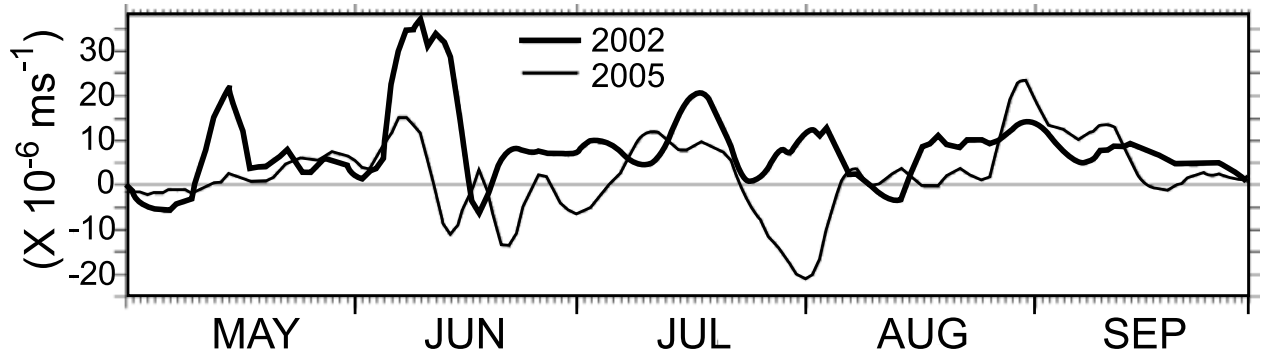

Figure 6b. Daily march of Ekman pumping velocity $\left(\times 10^{-6} \mathrm{~m} \mathrm{~s}^{-1}\right)$ derived from QuikSCAT in the coastal box during the summer monsoon seasons of 2002 (thick line) and 2005 (thin line). 
(a)

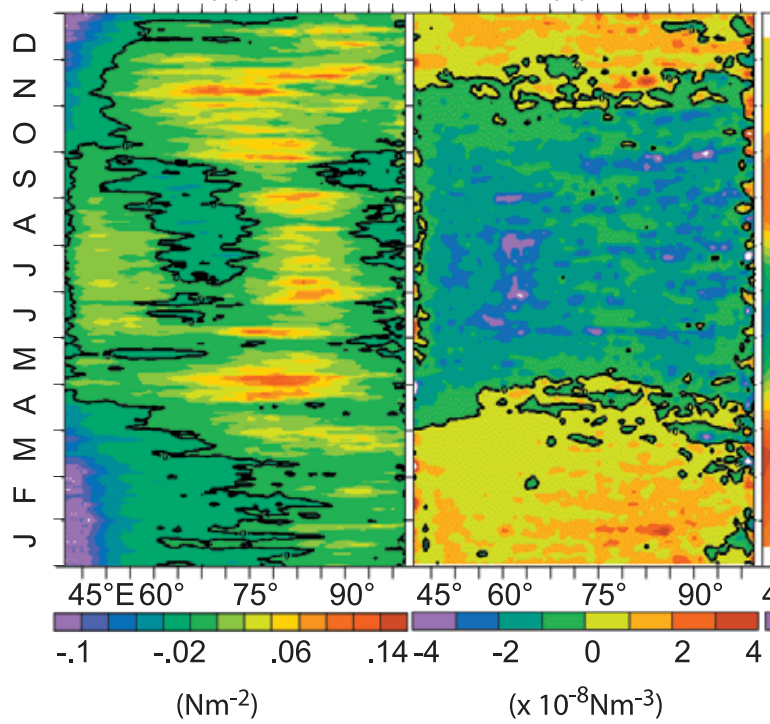

(c)

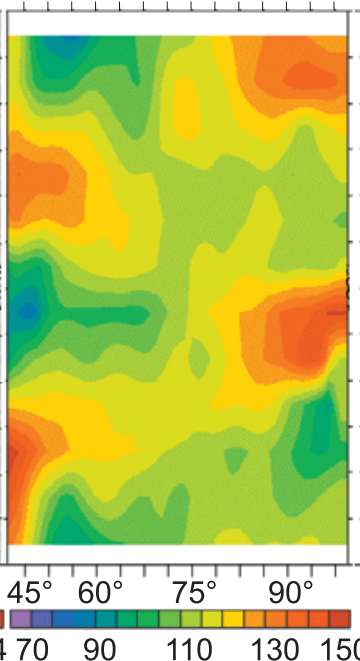

(d)

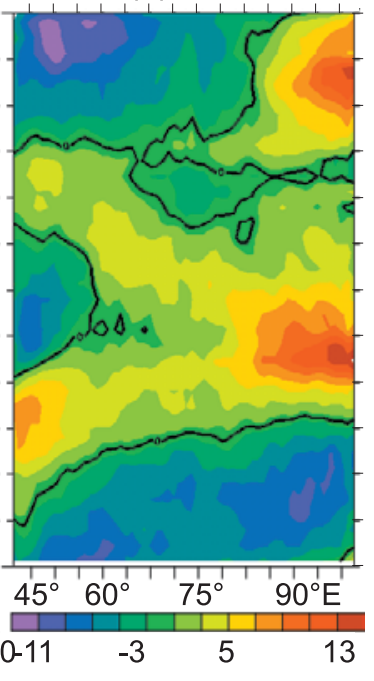

(m)

$(\mathrm{cm})$

Figure 7. Hovmüller fields of multiyear (2000-2006 in case of winds, 1998-2006 in case of SSH anomaly and Locarnini temperature climatology in case of D20) averages of (a) surface zonal wind stress $\left(\mathrm{N} \mathrm{m}^{-2}\right)$, (b) surface wind stress curl $\left(\mathrm{N} \mathrm{m}^{-3}\right)$, (c) D20 (meters), and (d) SSH anomaly (centimeters) along the equator $\left(1^{\circ} \mathrm{N}-1^{\circ} \mathrm{S}\right.$ average).

Indian Ocean [Potemra et al., 1991; Yu et al., 1991; McCreary et al., 1993; McCreary et al., 1996; Shankar et $a l ., 2002]$. The energy imparted by the surface winds propagate along the equatorial waveguide as upwelling/ downwelling Kelvin waves and traverse around the rim of Bay of Bengal $(\mathrm{BoB})$ and enter the SEAS. In addition, the alongshore winds in the coastal $\mathrm{BoB}$ also trigger and modulate the propagating Kelvin waves. The signature of this wave propagation is examined utilizing the satellite surface wind and satellite altimetry measurements along the equator. The observed zonal wind stress climatology (Figure 7a) is relatively stronger over the east central equator and shows strong intraseasonal variability with pronounced peaks during the monsoon transitions (resulting in Spring and Fall Wyrtki Jets). These westerly wind bursts produce downwelling Kelvin waves that propagate along the equator [Sengupta et al., 2007]. When these westerly wind bursts weaken or replaced by easterlies during winter, the upwelling Kelvin waves get triggered and propagate along the equator. In addition, the surface wind stress curl climatology along the equator (Figure $7 \mathrm{~b}$ ) is negative (positive) during April-November (December-March) that triggers eastward propagating downwelling (upwelling) Kelvin waves. The signature of these downwelling and upwelling Kelvin waves is very well reflected in the Hovmüller fields of D20 extracted from the temperature climatology [Locarnini et al., 2006] (Figure 7c) and SSH anomaly climatology (Figure 7d). The deepening of D20 and increase of SSH anomaly with eastward propagation during February-May and August-November is a clear manifestation of the downwelling Kelvin waves. On the other hand the shoaling of D20 and increase of negative SSH anomaly with eastward propagation during NovemberMarch is a clear manifestation of the upwelling Kelvin waves. Both the downwelling and upwelling Kelvin waves after impinging the Sumatra coast bifurcate and the northern branch propagates along the rim of the $\mathrm{BoB}$ before they reach the SEAS after about one month with a phase speed of $2.7 \mathrm{~m} / \mathrm{s}$ [Chelton et al., 1998]. In addition, these Kelvin waves also trigger Rossby waves that propagate westward both along the equator and off the equator.

[11] The observed annual cycle of zonal wind climatology (QuikSCAT) along the equator $\left(1^{\circ} \mathrm{S}-1^{\circ} \mathrm{N}\right.$ average) is shown for the years 2002-2006 (Figure 8a). The westerly wind bursts occur episodically with large intraseasonal variability among the years of study. These wind bursts are relatively weaker during January-March and during July-August. They are more pronounced during the monsoon transition periods namely during April-May and during October-November along the equator. The Fall Wyrtki Jet that occurs during October-November also triggers Kelvin waves that propagate eastward along the equator and reach the Sumatra coast. During December 2004-February 2005, the westerly winds are relatively short-lived and weaker along the equator when compared to the years 2002, 2003 and 2005. Owing to this the corresponding observed negative SSH anomaly is also much weaker in the equatorial Indian Ocean (Figure 8b). This suggests that the corresponding occurrence of relatively weaker upwelling Kelvin wave that has propagated into the SEAS by February-March 2005. Modeling studies [McCreary et al., 1993] have also shown the importance of along shore winds in the coastal regions of the BoB in triggering Kelvin waves that propagate into the SEAS. The equatorward alongshore surface wind stress over the western rim of the $\mathrm{BoB}\left(22^{\circ}\right.$ to $\left.6^{\circ} \mathrm{N}\right)$ (Figure $8 \mathrm{c}$ ) during October 2004 to February 2005 also shows relatively weaker fields suggestive of resultant weaker upwelling Kelvin waves. However, the corresponding alongshore winds over the eastern rim of the $\mathrm{BoB}$ did not show any perceptible 


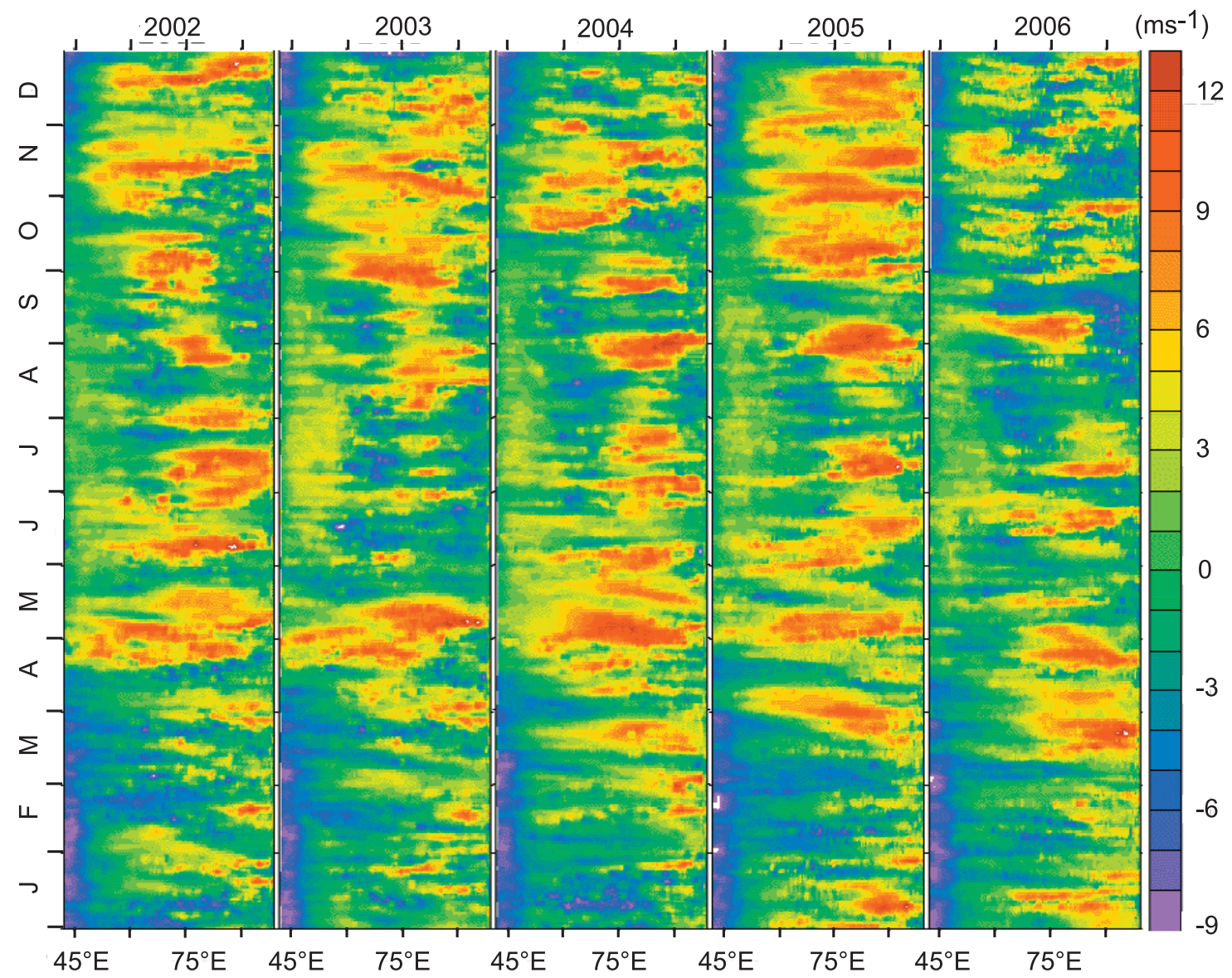

Figure 8a. Evolution of zonal surface wind $\left(\mathrm{m} \mathrm{s}^{-1}\right)$ along the equator $\left(1^{\circ} \mathrm{N}-1^{\circ} \mathrm{S}\right.$ average $)$ during $2002-2006$.

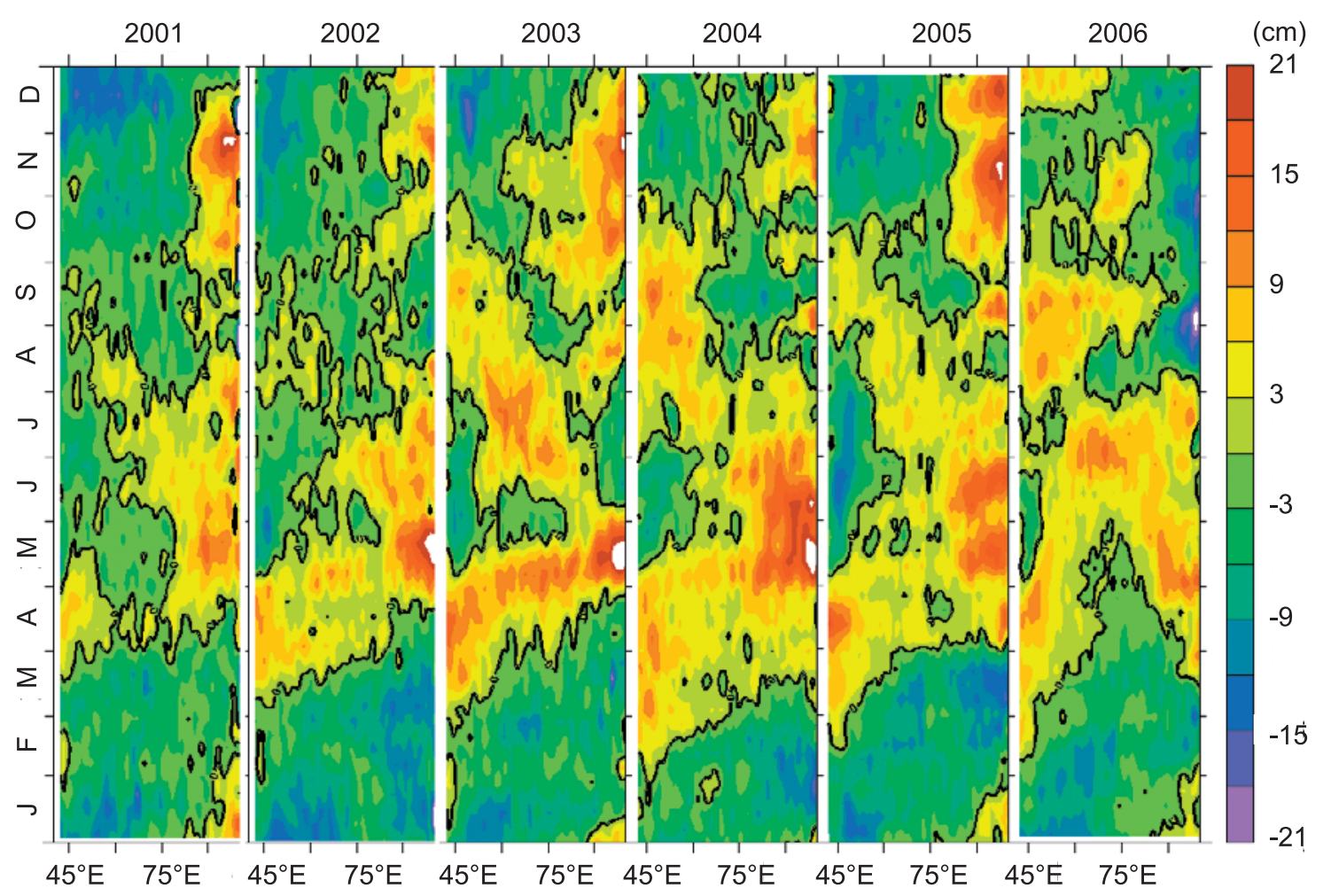

Figure 8b. Evolution of SSH anomaly (meters) along the equator $\left(1^{\circ} \mathrm{N}-1^{\circ} \mathrm{S}\right.$ average $)$ during $2001-2006$. 


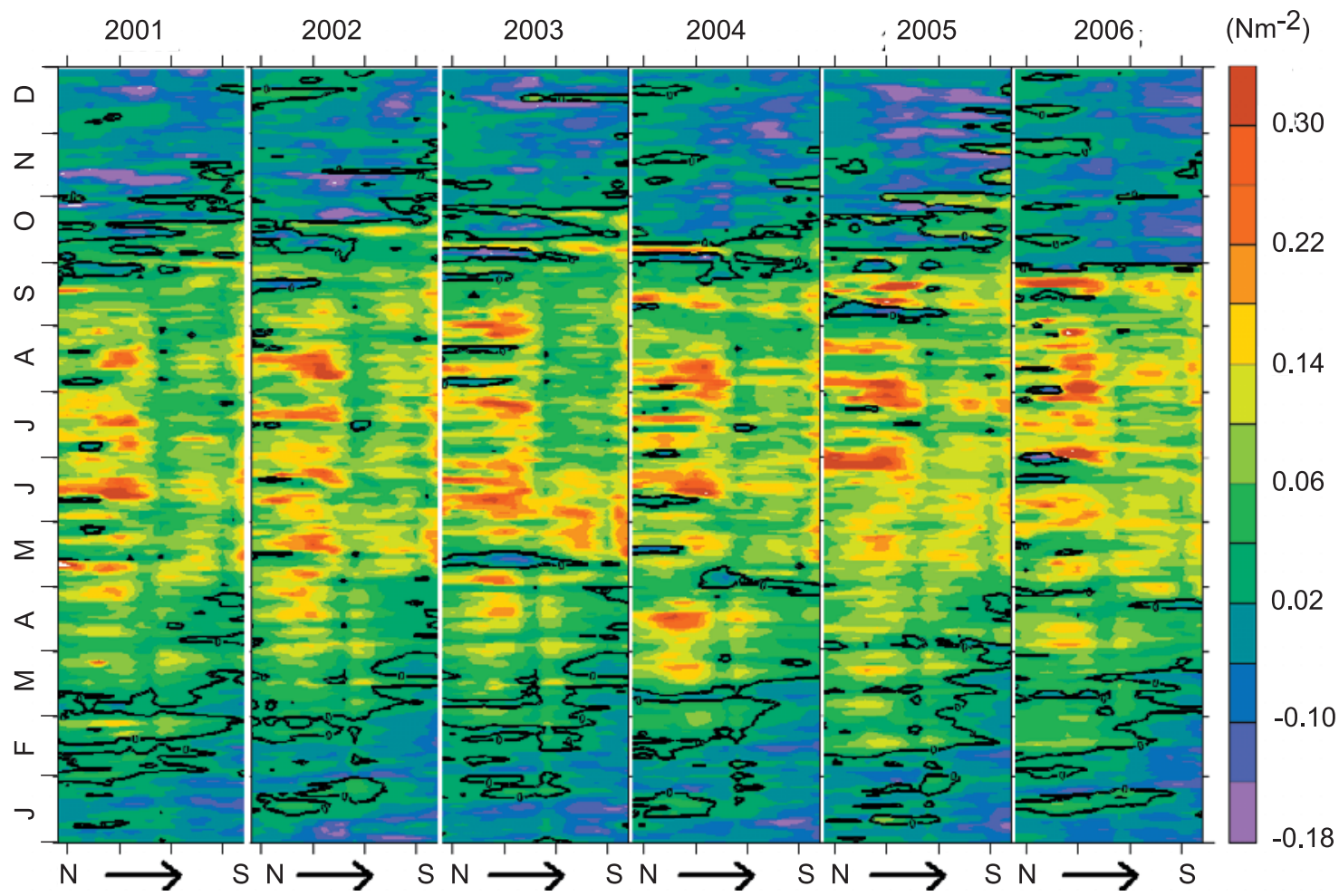

Figure 8c. Evolution of surface along-shore wind stress $\left(\mathrm{N} \mathrm{m}^{-2}\right)$ along the western rim of the Bay of Bengal during 2001-2006 $\left(1^{\circ}\right.$ boxes hugging the east coast of India: $22^{\circ} \mathrm{N}-6^{\circ} \mathrm{N}$ : northern end to southern end).

differences among the years of study (figure not shown). Thus the present analysis has clearly shown that, the remote forcing both from the equator and the western coastal BoB during winter of 2004-2005 is relatively weaker compared to the other years. This might have caused weaker upwelling during the SMS of 2005.

\subsection{Relative Importance of Local Versus Remote Forcing}

[12] The local forcing is characterized by alongshore wind stress off the southwest coast of India and the remote forcing is characterized by the coastally trapped propagating Kelvin waves that reach SEAS, triggered by both the equatorial zonal wind stress and the alongshore wind stress off the east coast of India. The observed time series of D25 and SSH anomaly (Figure 9) in the coastal box (shown in Figure 1) during 2002-2006 are utilized to seek the relationship between them through a correlation analysis. The correlation between these two parameters is 0.88 which is statistically significant at $99 \%$. Hence it can be concluded that SSH anomaly serves as a good proxy for D25 and accordingly SSH anomaly is utilized for correlation analysis. Shankar et al. [2002] have carried out a detailed study highlighting the relative importance of various processes both local and remote that modulate the sea level and circulation in the north Indian Ocean. Their study clearly revealed that the equatorial zonal winds and the alongshore winds off the Myanmar coast have shown a relatively weaker role in modulating the upwelling/downwelling cycles observed along the southwest coast of India. To delineate the relative importance of local versus remote forcing, following the results of Shankar et al. [2002], the $\mathrm{SSH}$ anomaly in the coastal box shown in Figure 1 (as a dependent variable) is correlated with the SSH anomaly in the rest of the basin (as independent variable) for different lags. The correlation fields for different lags of 2 to $12 \mathrm{~d}$ are contoured and presented in Figure 10. Large correlation values are only seen in the regions adjacent to west coast of India, the southern tip of India and Sri Lanka and in the south-central and western BoB. The magnitude of these correlation values rapidly decreased with increasing lags. The regions where the correlations are relatively large are well known for the propagating coastal Kelvin waves and westward propagating Rossby waves. Thus the observed SSH anomaly variability in the above mentioned regions can be attributed to the propagating wave fields. The largest correlation was found at $8 \mathrm{~d}$ lag implying that the propagating Kelvin waves around Sri Lanka play an important role in modulating the observed SSH anomaly in the coastal box. Similarly, influence of local alongshore wind-forcing is examined by correlating it with D25 and SSH anomaly in the coastal box and the correlations are 0.56 and 0.59 respectively significant at $99 \%$ confidence limits.

[13] The contribution of remote forcing from the south of Sri Lanka on the observed SSH anomaly in the coastal box (Figure 1) is also examined through a correlation analysis between SSH anomaly at the same box (as dependent variable) and anomalies of zonal winds (as independent variable) over the entire basin. The correlation contours are drawn for lags of 2 to $12 \mathrm{~d}$. Largest negative correlations are seen south of Indian peninsula suggesting strong relation between south of Sri Lanka zonal winds and SSH anomaly 


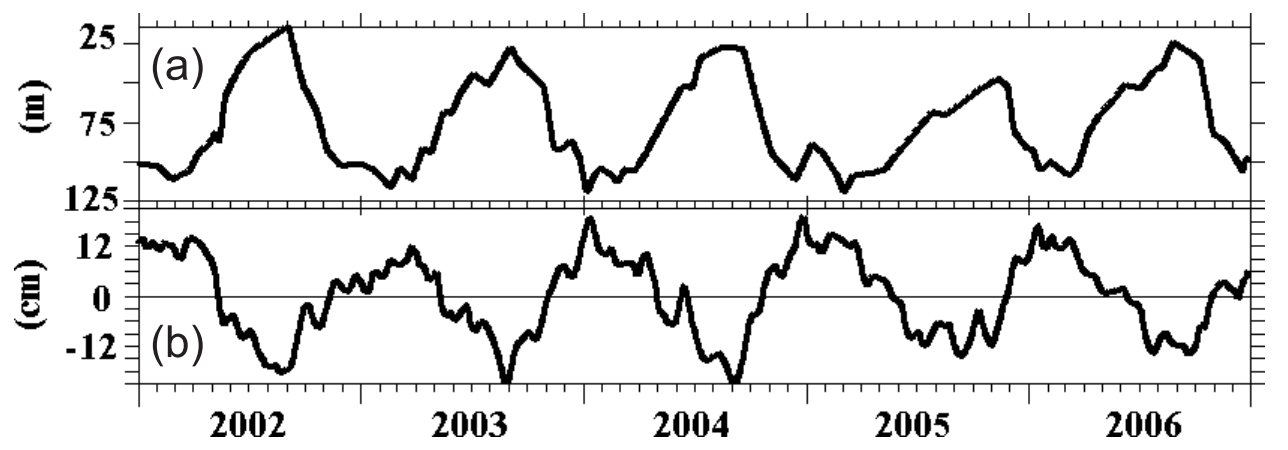

Figure 9. Time series of (a) D25 (meters) and (b) SSH anomaly (centimeters) (seasonal cycle removed) in the coastal box (shown in Figure 1) during 2002-2006.

in the coastal box (Figure 11) in agreement with Shankar et al. [2002]. The above analysis clearly showed the importance of the remote forcing through coastal trapped Kelvin waves excited by alongshore winds along southern Sri Lanka coast. The Rossby wave signals seen in Figure 10 in the south central Bay of Bengal are also may play an important role. The local alongshore winds together with the remote forcing along the southern coast of Sri Lanka may play an important role in bringing the observed interannual variability in the strength of upwelling in the SEAS region.

\section{Summary}

[14] The near-fortnightly systematic repeat XBT measurements made along the KK XBT transect during May 2002 to December 2006 have provided a unique and first of its kind time series data set to examine the evolution of nearsurface thermal structure and to describe the observed year-
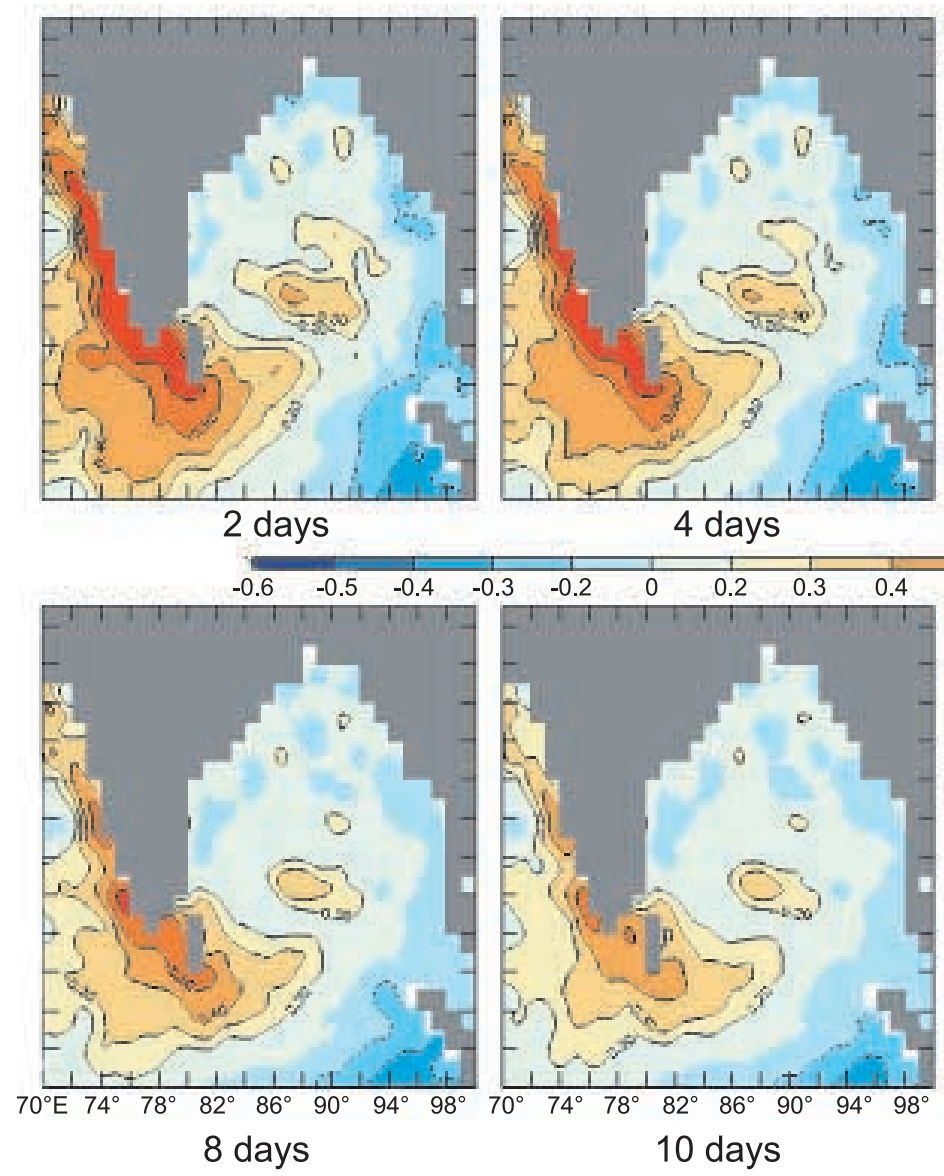

4 days

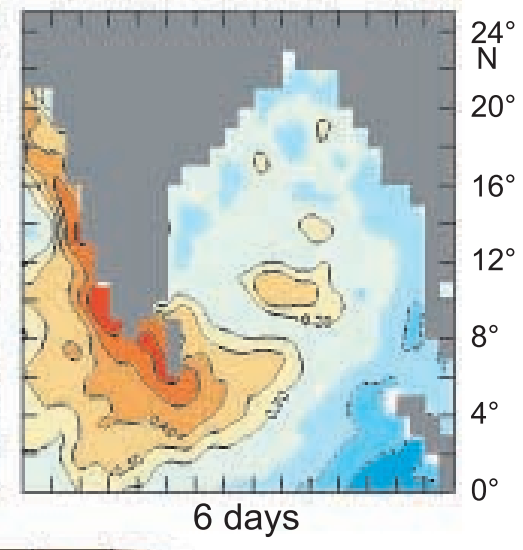

Figure 10. Lag correlation ( 2 to 12 d) between SSH anomaly in the coastal box (shown in Figure 1) and the rest of the basin. 


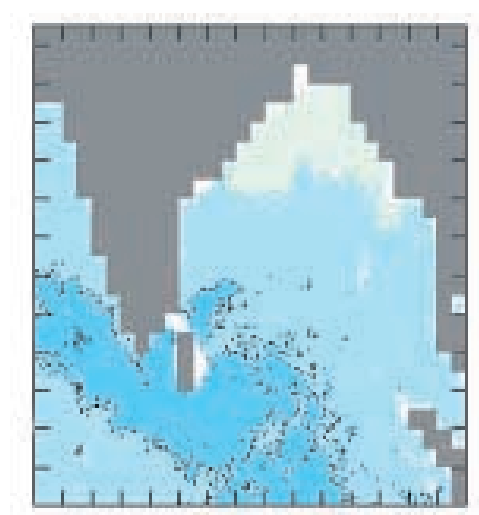

2 days

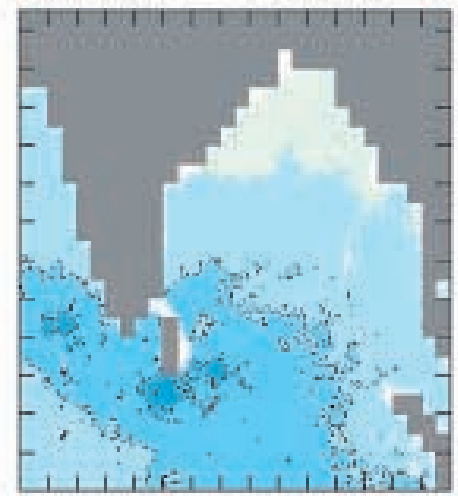

4 days

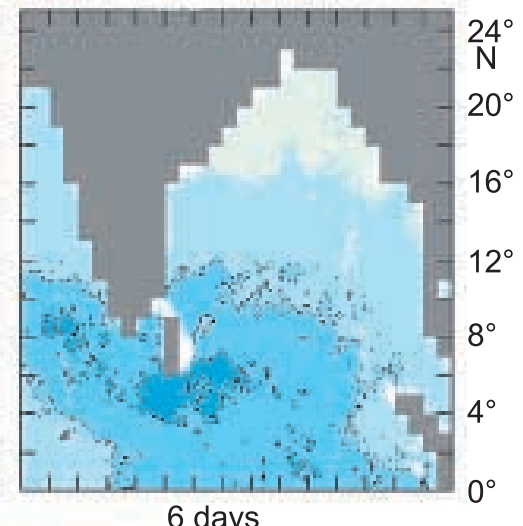

6 days

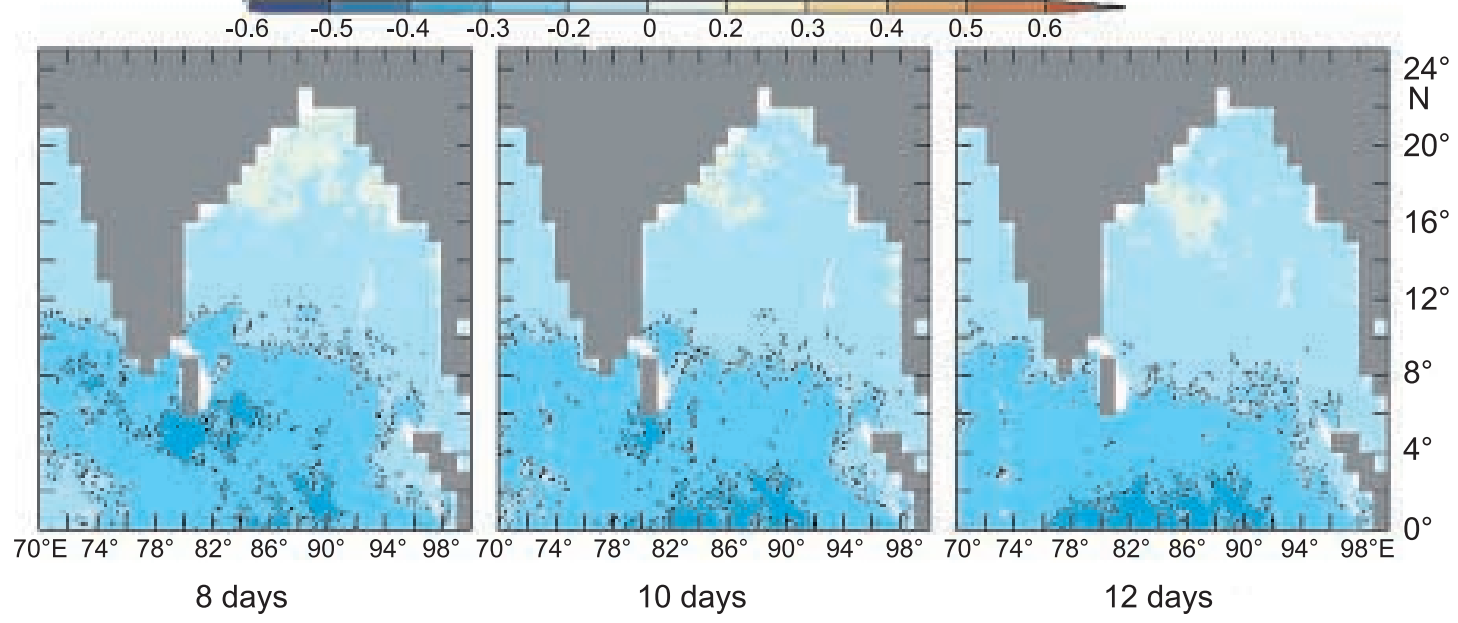

Figure 11. Lag correlation ( 2 to $12 \mathrm{~d}$ ) between zonal winds (seasonal cycle removed) at the equatorial region $\left(1^{\circ} \mathrm{S}-1^{\circ} \mathrm{N}\right)$ and $\mathrm{SSH}$ anomaly in the rest of the basin.

to-year variability of the summer monsoonal upwelling. Snapshot vertical thermal sections have shown a pronounced annual cycle with a bimodal structure in the near-surface isothermal layer and a unimodal structure in the thermocline. The upwelling characteristics observed during the SMS of 2002 and SMS of 2005 are distinctly different from those observed during the other years. During the SMS of 2005 (SMS of 2002), the upwelling is relatively weaker (stronger) than that of any other year. The upwelling (uplift of D25 in the thermocline) during the SMS of 2005 has persisted longer by about two months when compared to the other years. The observed negative $\mathrm{SSH}$ anomaly distribution along the KK XBT transect has also shown a similar pattern during the SMS of 2005. The alongshore equatorward wind stress has shown similar pattern of SSH anomaly, i.e., unusually lasted until November/December 2005. The surface wind stress curl has also shown stronger positive values during SMS of 2002 in comparison to SMS of 2005 lending support to stronger (weaker) upwelling during 2002 (2005). Interestingly the corresponding observed SST has shown prolonged cooling up to December, 2005 unlike any other year. During 2005 the secondary warming during postmonsoon season was relatively weaker and transient. During 2005, another parameter, the pelagic fish landings along the southwest coast of India, has also shown relatively lower values with prolonged extension until December. Thus five independent measurements, namely, D25, negative SSH anomaly, alongshore equatorward wind stress, SST and pelagic fish landings have all shown supportive evidence for upwelling lasting longer by about two months during 2005. The observed surface westerly winds along the equator during the winter of 2004-2005 are short-lived and relatively weaker resulting in the occurrence of weaker positive SSH anomaly. This has triggered a weaker upwelling Kelvin wave that has propagated into the SEAS by February-March 2005. This is further reinforced by the relatively weaker equatorward alongshore wind stress along the western rim of the $\mathrm{BoB}$ triggering weaker upwelling Kelvin waves.

[15] The present study provides the observational evidence in the SEAS on the relative importance of local versus remote forcing. The present analysis has clearly revealed that the alongshore wind stress off the southwest coast of India and the remote forcing from south of Sri Lanka is relatively more important forcing compared to the equatorial forcing influencing the upwelling signal in the LS during the SMS. Long time series measurements on nearsurface thermal structure from moored buoys deployed at few locations in the LS and off the east coast of India and numerical modeling studies are needed to quantify the 
relative importance of local and remote effects in forcing the observed upwelling in the LS during the SMS.

[16] Acknowledgments. We thank the Ministry of Earth Sciences, Government of India for the support through INCOIS, Hyderabad for the conduct of XBT surveys. We are grateful to J.P. McCreary (IPRC), Gary Meyers (CSIRO), Raghu Murtugudde (UMD), and D. Sengupta (IISc) for clarifications on the propagating waves along the equator. We also thank Fabian Durand whose valuable comments have helped in improving the manuscript. We acknowledge anonymous reviewers for their constructive comments that helped to improve the manuscript. We thank Shri Selvaraj, IAS, the Lakshadweep Administrator and his officers at Cochin for providing ship cabin accommodation continually. We thank the ship captains and other officers for permitting XBT measurements onboard passenger ships. The altimeter products were produced by SSALTO/ DUACS and distributed by AVISO, with support from CNES; the QuikSCAT data were produced by PODAAC at JPL NASA. The TMI data were downloaded from ftp://ftp.ssmi.com. The graphics are prepared with Ferret. This is NIO contribution 4332 .

\section{References}

Banse, K. (1958), On upwelling and bottom trawling off the southwest coast of India, J. Mar. Biol. Assoc. India, 1, 33-49.

Banse, K. (1968), Hydrography of the Arabian Sea shelf of India and Pakistan and effects on demersal fishes, Deep Sea Res., 15, 45-79.

Bruce, J. G., D. R. Johnson, and J. C. Kindle (1994), Evidence for eddy formation in the eastern Arabian Sea during the northeast monsoon, J. Geophys. Res., 99, 7651-7664, doi:10.1029/94JC00035.

Chelton, D. B., R. A. Deszoeke, and M. G. Schlax (1998), Geographical variability of the first baroclinic Rossby radius of deformation, $J$. Phys. Oceanogr., 28, 433-460, doi:10.1175/1520-0485(1998)028< 0433:GVOTFB $>2.0 . \mathrm{CO} ; 2$

Clarke, A. J. (1983), The reflection of equatorial waves from oceanic boundaries, J. Phys. Oceanogr., 13, 1193-1207, doi:10.1175/1520-0485 (1983)013<1193:TROEWF>2.0.CO;2.

Cutler, N., and J. C. Swallow (1984), Surface Currents of the Indian Ocean (to $25^{\circ} \mathrm{S}, 100^{\circ} \mathrm{E}$ ), Inst. of Oceanogr. Sci., Wormley, U.K.

Gopalakrishna, V. V., Z. Johnson, G. Salgaonkar, K. Nisha, C. K. Rajan, and R. R. Rao (2005), Observed variability of sea surface salinity and thermal inversions in the Lakshadweep Sea during contrast monsoons, Geophys. Res. Lett., 32, L18605, doi:10.1029/2005GL023280.

Han, W., and P. J. Webster (2002), Forcing mechanisms of sea level interannual variability in the Bay of Bengal, J. Phys. Oceanogr., 32, 216239, doi:10.1175/1520-0485(2002)032<0216:FMOSLI >2.0.CO;2.

Johannessen, O. M., G. Subbaraju, and J. Blindheim (1987), Seasonal variations of the oceanographic conditions off the southwest coast of India during 1971-1975, Fisk Dir. Skr Hav Unders, 18, 247-261.

Locarnini, R. A., A. V. Mishonov, J. I. Antonov, T. P. Boyer, and H. E. Garcia (2006), World Ocean Atlas 2005, vol. 1, Temperature, NOAA Atlas NESDIS 61 (1), 182 pp., Natl. Oceanic and Atmos. Admin., Silver Spring, Md.

Madhupratap, M., S. R. Shetye, K. N. V. Nair, and S. R. Sreekumaran Nair (1994), Oil sardine and Indian mackerel: Their fishery, problems and coastal oceanography, Curr. Sci., 66, 340-348.

Madhupratap, M., S. Prasanna Kumar, P. M. A. Bhattathiri, M. Dileep Kumar, S. Raghukumar, K. K. C. Nair, and N. Ramaiah (1996), Mechanism of the biological response to winter cooling in the north eastern Arabian Sea, Nature, 384, 549-552, doi:10.1038/384549a0.

Madhupratap, M., K. N. V. Nair, T. C. Gopalakrishna, P. Haridas, K. K. C. Nair, P. Venugopal, and M. Gauns (2001), Arabian Sea oceanography and fisheries of the west coast of India, Curr. Sci., 81, 355-361.

McCreary, J. P., and S. Y. Chao (1985), Three-dimensional shelf circulation along an eastern ocean boundary, J. Mar. Res., 43, 13-36.

McCreary, J. P., P. K. Kundu, and R. L. Molinari (1993), A numerical investigation of the dynamics, thermodynamics and mixed layer processes in the Indian Ocean, Prog. Oceanogr., 31, 181-244, doi:10.1016/0079-6611(93)90002-U.

McCreary, J. P., W. Han, D. Shankar, and S. R. Shetye (1996), Dynamics of the East India Coastal Current: 2. Numerical solutions, J. Geophys. Res. 101, 13,993-14,010, doi:10.1029/96JC00560.
Potemra, J. T., and M. E. Luther (1991), The seasonal circulation of the upper ocean in the Bay of Bengal, J. Geophys. Res., 96, 12,667-12,683, doi:10.1029/91JC01045.

Rao, R. R., and R. Sivakumar (1999), On the possible mechanisms of the evolution of a mini-warm pool during the pre-summer monsoon season and the onset vortex in the south eastern Arabian Sea, Q.J.R. Meteorol. Soc., 125, 787-809, doi:10.1002/qj.49712555503.

Sengupta, D., R. Senan, B. N. Goswami, and J. Vialard (2007), Intraseasonal variability of equatorial Indian Ocean zonal currents, J. Clim., 20(13), 3036-3055, doi:10.1175/JCLI4166.1.

Shankar, D., and S. R. Shetye (1997), On the dynamics of the Lakshdweep high and low in the southeastern Arabian Sea, J. Geophys. Res., 102, 12,551 - 12,562, doi:10.1029/97JC00465.

Shankar, D., P. N. Vinayachandran, and A. S. Unnikrishnan (2002), The monsoon currents in the north Indian Ocean, Prog. Oceanogr., 52, $63-$ 120, doi:10.1016/S0079-6611(02)00024-1.

Shankar, D., S. S. C. Shenoi, R. K. Nayak, P. N. Vinayachandran, G. Nampoothiri, A. M. Almeida, G. S. Michael, M. R. Rameshkumar, D. Sundar, and O. P. Sreejith (2005), Hydrography of the eastern Arabian Sea during summer monsoon 2002, J. Earth Syst. Sci., 114, 459-474, doi:10.1007/BF02702023.

Sharma, G. S. (1968), Seasonal variation of some hydrographic properties of the shelf waters off the west coast of India, Bull. Natl. Inst. Sci. India, $38,263-276$

Shenoi, S. S. C., D. Shankar, and S. R. Shetye (1999), On the sea surface temperature high in the Lakshadweep Sea before the onset of the southwest monsoon, J. Geophys. Res., 104, 15,703-15,712, doi:10.1029/ 1998JC900080

Shenoi, S. S. C., et al. (2005), Hydrography and water masses in the southeastern Arabian Sea during March-June 2003, J. Earth Syst. Sci., 114, 475-491, doi:10.1007/BF02702024.

Shetye, S. R. (1984), Seasonal variability of temperature fields off the southwest coast of India, Proc. Indian Acad. Sci. Earth Planet. Sci., 93, 399-411.

Shetye, S. R., and S. S. C. Shenoi (1988), Seasonal cycle of surface circulation in the coastal North Indian Ocean, Proc. Indian Acad. Sci. Earth Planet. Sci., 97, 53-62.

Shetye, S. R., S. S. C. Shenoi, M. K. Antony, and V. Krishna Kumar (1985), Monthly mean wind stress distribution along the coast of the North Indian Ocean, Proc. Indian Acad. Sci. Earth Planet. Sci., 94, 129-137.

Shetye, S. R., A. D. Gouveia, S. S. C. Shenoi, D. Sundar, G. S. Michael, A. M. Almeida, and K. Santanam (1990), Hydrography and circulation off the west coast of India during south west monsoon of 1987, J. Mar. Res., 48, 359-378.

Srinath, M., S. Kuriekose, P. L. Amonini, C. J. Prasad, K. Ramani, and M. R. Beena (2006), Marine fish landings in India: 1985-2004 estimates and trends, Spec. Publ. 89, Cent. Mar. Fish. Res. inst., Koshi, India.

Thadathil, P., and A. Gosh (1992), Surface layer temperature inversion in the Arabian Sea during winter, J. Oceanogr., 48, 293-304, doi:10.1007/ BF02233989.

Yu, L., J. J. O'Brien, and J. Yang (1991), On the remote forcing of the circulation in the Bay of Bengal, J. Geophys. Res., 96, 20,449-20,454, doi:10.1029/91JC02424.

N. Aneeshkumar, K. Girish, Z. Johnson, and C. K. Rajan, Department of Atmospheric Sciences, Cochin University of Science and Technology, Fine Arts Avenue, Kochi 682 016, India. (aneeshkumar@email.com; girish oce@yahoo.com; johnson_zacharia@yahoo.co.uk; rajan@cusat.ac.in)

M. S. Girishkumar and R. R. Rao, Naval Physical and Oceanographic Laboratory, Trikkakara, Kochi 682 022, India. (giriemet@gmail.com; rokkamrr@yahoo.com)

V. V. Gopalakrishna, K. Nisha, T. Pankajakshan, and S. Rajesh, National Institute of Oceanography, Dona Paula, Goa 403 004, India. (gopal@ nio.org; knisha@nio.org; pankaj@nio.org; rajeshsikhakolli@gmail.com)

M. Ravichandran, Indian National Centre for Ocean Information Services, Ocean Valley, P B no: 21, IDA Jeedimetla P O, Hyderabad 500 055, India. (ravi@incois.gov.in)

M. Srinath, Central Marine Fisheries Research Institute, Dr. Salim Ali Road, Kochi 682 016, India. (mudumby@yahoo.com) 